\title{
The effects of individual or blended essential oils on rumen gas production and ammonia accumulation in vitro
}

K Mitchell, S Chikunya

Writtle College, Essex, United Kingdom

Email: katherine.mitchell@writtle.ac.uk

Introduction The incorporation of essential oils into ruminant diets has the potential to beneficially modify rumen fermentation. In the literature, essential oils have been reported to alter several rumen parameters such as molar proportions of volatile fatty acids (VFA), methane production and amino acid degradation (reviewed by Calsamiglia et al. 2007). The majority of studies that have investigated the effects of essential oils have largely focused on inclusion levels of individual oils. Few studies have investigated the potential synergistic effects of blending different essential oils. The aim of this study was to analyse the effects of three essential oils, eugenol, limonene and terpinene and their respective blends on rumen fermentation in vitro.

Materials and methods A 70:30 grass hay (Lolium perenne) and concentrate basal diet milled through a $1 \mathrm{~mm}$ screen, was incubated in $125 \mathrm{ml}$ serum bottles. Incubation buffer $(90 \mathrm{ml})$, prepared according to Theodorou et al. (1994), and $10 \mathrm{ml}$ of strained rumen fluid were added to each bottle. The rumen fluid used was sourced from three sheep rumens obtained from a local abattoir. Essential oils were added to the bottles to achieve a dosage level of $500 \mathrm{mg} /$ litre either as individual or blended (50:50) mixes of essential oils. The seven experimental treatments were as follows: control (CON, unsupplemented diet), eugenol (EUG, 100\%), limonene (LIM, 100\%), terpinene (TER, 100\%), eugenol + limonene (EuLi, 50:50), limonene + terpinene $(\mathrm{LiTe}, 50: 50)$, terpinene + eugenol $(\mathrm{TeEu}, 50: 50)$. Four replicates of each treatment were incubated and gas production was measured at 3, 6, 12, 24, 48 and 72 hours using a pressure transducer (Mauricio, et al 1999). Another set of extra bottles, treated as above, were incubated alongside and stopped after 12, 24, 48 and 72 hours and their contents analysed for ammonia nitrogen $\left(\mathrm{NH}_{3}-\mathrm{N}\right)$ and VFA. Treatment effects were analysed using analysis of variance with Genstat $11^{\text {th }}$ Edition.

Results Gas production data are summarised in Table 1. After 3, 6, 12 and 24 hours of incubation all essential treatments significantly reduced gas production compared to the control $(\mathrm{P}<0.001)$. Blending terpinene and eugenol (TeEu) consistently caused the greatest reduction in gas production compared to other treatments at all times $(\mathrm{P}<0.001)$. Other essential oil blends (EuLi and LiTe) generally did not alter gas production compared to individual supplements of these essential oils. The effects of essential oils on $\mathrm{NH}_{3}-\mathrm{N}$ concentration are shown in Table 2. There was no difference in $\mathrm{NH}_{3}-\mathrm{N}$ after 12 hours of incubation across all treatments. In general, all essential oil treatments reduced $\mathrm{NH}_{3}-\mathrm{N}_{\text {concentration at } 24}$ and 48 hours compared to the control. LIM elicited the most significant reduction in $\mathrm{NH}_{3}-\mathrm{N}$ at 24 hours.

Table 1 Effects of either individual or combinations (50:50) of essential oils on cumulative gas production (ml/g DM) in vitro $(\mathrm{n}=4)$

\begin{tabular}{cccccccccc}
\hline \hline & \multicolumn{1}{c}{ Experimental Treatments } & \multicolumn{1}{c}{} \\
Time (hr) & CON & EUG & LIM & TER & EuLi & LiTe & TeEu & sed & $P$-value \\
\hline 3 & 31 & 19 & 21 & 23 & 18 & 23 & 16 & 1.4 & $\mathrm{P}<0.001$ \\
6 & 60 & 39 & 40 & 41 & 35 & 44 & 33 & 2.8 & $\mathrm{P}<0.001$ \\
12 & 98 & 72 & 66 & 72 & 64 & 72 & 57 & 5.1 & $\mathrm{P}<0.001$ \\
24 & 138 & 118 & 83 & 91 & 90 & 88 & 82 & 4.7 & $\mathrm{P}<0.001$ \\
48 & 178 & 174 & 116 & 116 & 117 & 109 & 104 & 7.2 & $\mathrm{P}<0.001$ \\
72 & 193 & 193 & 136 & 134 & 132 & 126 & 114 & 8.0 & $\mathrm{P}<0.001$ \\
\hline \hline
\end{tabular}

Table 2 Effects of either individual or combinations (50:50) of essential oils on $\mathrm{NH}_{3}-\mathrm{N}$ (mg/litre) concentration in vitro

\begin{tabular}{cccccccccc}
\hline & \multicolumn{1}{c}{ Experimental Treatments } & \multicolumn{1}{c}{} \\
Time $(\mathrm{hr})$ & CON & EUG & LIM & TER & EuLi & LiTe & TeEu & sed & $P$-value \\
\hline 12 & 242 & 256 & 258 & 259 & 250 & 253 & 262 & 5.7 & NS \\
24 & 294 & 308 & 272 & 273 & 281 & 283 & 288 & 6.9 & $\mathrm{P}=0.001$ \\
48 & 383 & 343 & 296 & 302 & 318 & 297 & 316 & 13.2 & $\mathrm{P}=0.002$ \\
72 & 422 & 352 & 333 & 328 & 354 & 343 & 359 & 8.2 & $\mathrm{P}<0.001$ \\
\hline \hline
\end{tabular}

Conclusion This study demonstrates that essential oils have antimicrobial activities that depress both gas production and $\mathrm{NH}_{3}-\mathrm{N}$ concentration compared to unsupplemented controls. Although essential oil combinations reduced gas production they appear not to be as effective as individual unblended essential oils at reducing ammonia production in vitro.

\section{References}

Calsamiglia, S., Busquet, M., Cardozo, P.W., Castillejos, L. and Ferret, A. 2007. Journal of Dairy Science 90, $2580-2595$. Mauricio, R.M., Mould, F.L., Dhanoa, M.S., Owen, E., Channa, K.S. and Theodorou, M.K. 1999. Animal Feed Science and Technology 79, 321-330

Theodorou, M.K., Williams, B.A., Dhanoa, M.S., McAllan, A.B., and France, J. 1994. Animal Feed Science and Technology 48, 185-197. 